\title{
EVOLUCIÓN DEL RÉGIMEN AMBIENTAL DE LA ACUICULTURA EN CHILE
}

\author{
[Evolution of the Aquaculture Environmental Regime in Chile]
}

\author{
Jessica Fuentes Olmos* \\ Pontificia Universidad Católica de Valparaíso, Chile
}

\begin{abstract}
Resumen
El crecimiento de la acuicultura ha causado problemas ambientales difíciles de abordar desde la perspectiva tradicional de la regulación pesquera y la necesidad de controlarlos ha desafiado los pilares fundamentales de la intervención estatal en el ejercicio de la actividad económica. Nuevos instrumentos para ser utilizados en la regulación, como el enfoque precautorio y el ecosistémico, la planificación espacial y el crecimiento de la producción asociado al desempeño ambiental aparecen como alternativas que requieren un análisis acerca de su alcance desde la perspectiva de las limitaciones constitucionales que pueden ser impuestas a la actividad económica.
\end{abstract}

Palabras Clave

Acuicultura - Enfoque precautorio .

\begin{abstract}
The growth of aquaculture has caused environmental issues that have been hard to deal with from the traditional fishing regulation perspective. The need to control said problems has challenged the basic foundations of State intervention of the exercise of economic activities. New instruments to be used in the regulation, such as the precautionary and ecosystembased approach, space planning and production increase related to environmental performance arise as alternatives that require an analysis of their scope from the constitutional limitations perspective that may be imposed to the economic activity.

\section{KeYwords}

Aquaculture - Precautionary approach.
\end{abstract}

RECIBIDO el 29 de abril y ACEPTADo el 28 de mayo de 2014

* Profesora de Derecho Constitucional de la Escuela de Derecho de la Pontificia Universidad Católica de Valparaíso. Dirección postal: Bellavista 168 piso 18, edificio Centenario, Valparaíso, Chile. Correo electrónico fo.jessica@gmail.com. 


\section{INTRODUCCIÓN ${ }^{1}$}

La acuicultura es una actividad productiva que puede ser calificada de reciente en Chile, dado que su historia apenas excede de treinta años a escala comercial. Las primeras experiencias se remontan a la década de los setenta con proyectos pilotos realizados con el apoyo de Fundación Chile. En la actualidad, Chile es uno de los países acuicultores más importantes del mundo: el segundo productor mundial de salmónidos ${ }^{2}$ y de mitílidos ${ }^{3}$.

La acuicultura es una actividad productiva que se basa en el uso de recursos naturales y genera distintos impactos, los que dependen del tipo de cultivo, del nivel de producción, del sector de emplazamiento, del entorno circundante, entre otros factores. Así las cosas, es evidente que la acuicultura genera externalidades negativas que deben ser prevenidas y controladas por el Estado y de allí que se trate de una actividad regulada. Por otro lado, la actividad de acuicultura requiere principalmente de espacios de borde costero ${ }^{4}$ en los que compite con otros actores.

${ }^{1}$ Abreviaturas: ISA: sigla en inglés de la anemia infecciosa del salmón que es una enfermedad que afecta a los salmones, particularmente a la especie salmón del Atlántico (Salmo salar); LBGMA.= Ley $\mathrm{N}^{\circ} 19.300$ de Bases generales del medio ambiente; LGPA. $=$ Ley $\mathrm{N}^{\circ} 18.892$ General de pesca y acuicultura cuyo texto refundido, coordinado y sistematizado fue fijado por el Decreto supremo $N^{\circ} 430$ de 1991, del Ministerio de Economía; Ministerio de Economía, Fomento y Reconstrucción (hoy: “y Turismo"); RAMA. = Reglamento ambiental para la acuicultura aprobado por Decreto supremo $\mathrm{N}^{\circ} 320$ de 2001 del Ministerio de Economía, Fomento y Turismo; RESA. = "Reglamento sanitario" cuyo nombre oficial es el Reglamento de medidas de protección, control y erradicación de enfermedades de alto riesgo para las especies hidrobiológicas, aprobado por Decreto supremo $N^{\circ} 319$ de 2001 del Ministerio de Economía, Fomento y Turismo.

${ }^{2}$ Denominación genérica utilizada en el artículo 21 bis letra a) del Decreto supremo N 290 de 1993 del Ministerio de Economía, Fomento y Turismo y que agrupa a las especies salmón del Atlántico, salmón plateado o coho, salmón rey, salmón cereza, salmón keta, salmón rosado, trucha arcoíris, trucha café, trucha de arroyo y trucha de la montaña.

${ }^{3}$ Denominación genérica utilizada en el artículo 21 bis letra b) del Decreto supremo N $^{\circ} 290$ de 1993 del Ministerio de Economía, Fomento y Turismo y que agrupa a las especies cholga, chorito y choro.

${ }^{4}$ Conforme al artículo 2 de la "Política Nacional de Uso del Borde Costero" establecida mediante Decreto supremo N ${ }^{\circ} 475$ de 1994 del Ministerio de Defensa Nacional, publicado en el Diario Oficial de 11 de enero de 1995, el borde costero es "aquella franja del territorio que comprende los terrenos de playa fiscales situados en el litoral, la playa, las bahias, golfos, estrechos y canales interiores, y el mar territorial de la República, que se encuentran sujetos al control, fiscalización y supervigilancia del Ministerio de Defensa Nacional, Subsecretaria de Marina" . 
En el año 2003 se emitió una "Política Nacional de Acuicultura", instrumento directivo dirigido a sentar las bases del desarrollo de la acuicultura nacional; pero resultó ineficaz para orientar las conductas: en el período 2007-2010 se llegó a la más grave crisis vivida por el sector salmonicultor, lo que obligó a refundar las bases de su regulación. Destacable es que en la época de crisis la industria, siempre reticente a la intervención estatal, exigió una actividad intervencionista que se reflejara en la regulación y en la fiscalización.

En el presente artículo se pretende dar cuenta de los principales problemas ambientales que ha debido enfrentar la acuicultura y la normativa que ha sido dictada, analizando los derechos y limitaciones constitucionales en que se sustentan las decisiones adoptadas, así como las inconsistencias que se derivan de un cambio de enfoque que va desde la promoción de la actividad económica con una intervención estatal mínima (propia de una visión liberal que tiene como pilares los derechos constitucionales reconocidos en materia económica), a una perspectiva que eleva a prioritario el deber estatal de tutelar la preservación de la naturaleza. A esto se adicionan nuevos instrumentos para abordar con mayor eficiencia y oportunidad los problemas que pueden presentarse a futuro, como el enfoque precautorio, el ecosistémico y la planificación espacial, pero el desafío estará en determinar el alcance que ellos pueden tener y las limitaciones a que se ven sometidos.

El objetivo de este artículo será entonces sentar las bases para orientar futuras regulaciones para este sector económico. Para tales efectos el presente trabajo ha sido dividido de la siguiente manera: en primer lugar, se hará una breve caracterización de la actividad de la acuicultura, a fin de precisar las particularidades de su regulación, especialmente lo referido a los derechos constitucionales; en segundo lugar, se revisará la evolución de la normativa ambiental aplicable a la acuicultura; en tercer lugar, se realizará una evaluación crítica de la normativa ambiental aplicable a la acuicultura y de los nuevos instrumentos que pueden ser utilizados, para culminar con el último apartado de conclusiones.

\section{LA ACUICULTURA Y LOS DERECHOS CONSTITUCIONALES EN QUE SE BASA SU REGULACIÓN}

\section{Caracterización de la actividad de acuicultura.}

La acuicultura es una actividad que se desarrolla sobre distintos recursos hidrobiológicos, siendo los más importantes en Chile los salmónidos y mitílidos.

${ }^{5}$ Decreto supremo $\mathrm{N}^{\circ} 125$ de 2003 del Ministerio de Economía, Fomento y Turismo. 
Para el cultivo se requiere la utilización de bienes nacionales: porciones de agua y fondo de mar, playa, terrenos de playa y en ocasiones también ríos y lagos navegables ${ }^{6}$. Por este motivo se requiere el otorgamiento de una concesión de acuicultura, la que a su vez solo puede ser solicitada en lo que se denominan las áreas apropiadas para la acuicultura ${ }^{7}$. Este requisito fue instaurado en el año 1991 a través de la Ley $\mathrm{N}^{\circ} 19.079$ que modificó la LGPA. introduciendo una regulación específica para la acuicultura que hasta esa fecha se sometía a las disposiciones pesqueras (aprobación técnica de los proyectos) y de las concesiones marítimas (uso territorial marítimo, lacustre y fluvial).

Nunca se dictaron áreas apropiadas para la acuicultura en ríos y lagos, por lo que las concesiones aún existentes en dichos sectores obedecen a dos situaciones: a) concesiones marítimas obtenidas antes de 1991; o, b) titulares que a la fecha de entrada en vigencia de la ley 19.079 contaban con la autorización técnica de su actividad por parte de la Subsecretaría de Pesca y sólo estaba pendiente la obtención de la concesión marítima, resultando favorecidos por la disposición transitoria $5^{\text {a }}$ de la LGPA que establecía que los titulares de tales autorizaciones tenían el derecho a acceder a la concesión marítima conforme a las normas previas a la modificación legal.

En el año 2010 se elimina de la LGPA. ${ }^{8}$ la posibilidad de establecer áreas apropiadas para la acuicultura en ríos no navegables y en lagos, sean o no navegables (posibilidad que otorgaba la ley pero que nunca se llevó a la práctica). Sólo se autoriza establecer áreas apropiadas en ríos navegables para realizar acuicultura de carácter extensivo?.

$\mathrm{Al}$ establecer áreas apropiadas para la acuicultura se requiere consultar a los organismos encargados de los usos alternativos de dichas aguas y elaborar estudios que consideren variables medioambientales, áreas protegidas, caletas pesqueras, entre otras. Así en el año 1991 ya se preveía que la promoción de esta actividad ejercería presión sobre el borde costero pudiendo generar conflictos con otros usos del mismo, aún cuando a esa fecha la ocupación no era tan importante aunque sí lo era la actividad pesquera.

De este modo, el legislador pretendió establecer un instrumento ad hoc

${ }^{6}$ Sectores que con de competencia del Ministerio de Defensa Nacional, de acuerdo al Decreto con fuerza de ley $\mathrm{N}^{\circ} 340$ de 1960 . Se encuentra actualmente en trámite el proyecto de ley Boletin 8467-12 que pretende traspasar la competencia sobre el borde costero desde el Ministerio de Defensa Nacional al Ministerio de Bienes Nacionales.

${ }^{7}$ Artículo 67 LGPA.

${ }^{8}$ Modificación introducida por la Ley $\mathrm{N}^{\circ} 20.434$.

9 Sistema de producción extensivo: cultivo de recursos hidrobiológicos cuya alimentación se realiza en forma natural o con escasa intervención antrópica. Artículo $2^{\circ}$ letra r) RAMA. 
para determinar dónde se podía hacer acuicultura sin entrar en conflictos con otros usos. Sin embargo, en la práctica los estudios técnicos exigidos por la LGPA. se limitaron a determinar cartográficamente los espacios que por defecto no eran reclamados por otros usuarios del borde costero, quedando asignadas a la acuicultura las áreas que no recibieron oposición, sin que se consideraran las condiciones que son esenciales para obtener un buen desempeño ambiental de la actividad como la profundidad del sector, la velocidad de corrientes, entre otras, lo que en gran parte explica los problemas posteriores.

Cuando se fijaron las áreas apropiadas para la acuicultura no existía una cartografía adecuada para la actividad, por lo cual se utilizaron las cartas de navegación existentes que, a falta de la tecnología actual, no tenían referencia geodésica sino astronómica y, por ende, no daban cuenta de la real configuración de la costa. Esto llevó a que se entregaran en el tiempo concesiones de acuicultura cuyas coordenadas no se ajustaban a la realidad y fueron entregadas en los sectores más cercanos a lo solicitado. Esto llevó al mal emplazamiento de las concesiones, requiriéndose iniciar proyectos de regularización mediante los que se elaboraron nuevas cartas y se traspasaron a ellas las concesiones otorgadas. Este proceso comenzó en el año 2002 y recién estará terminando entre 2014 y 2015.

Debido a que la acuicultura se desarrolla en el medio marino, lacustre o fluvial, los acuicultores comparten las mismas condiciones ambientales con sus vecinos, sean acuicultores u otros usuarios. Esto determina la dependencia de todos de las condiciones del medio que comparten y la incidencia mutua de la actividad de cada uno sobre los otros. Por su parte, con el crecimiento de la actividad especialmente la salmonicultora, aumentó la actividad de los prestadores de servicios que realizan actividades anexas al cultivo. Por ejemplo, el transporte de los peces desde el centro de cultivo a la planta de proceso, los muestreos de los peces para determinar su estado de salud, el lavado de las redes de cultivo, entre otros, son procesos realizados por terceros.

Debe mencionarse que existen etapas de la producción de acuicultura que se realizan en tierra con derechos de aprovechamientos de agua. Lo importante es que en este caso no existe una instalación en la columna de agua del lago, río o del mar, sino que la actividad se realiza en piscinas, estanques o cualquier otro tipo de estructura de cultivo ${ }^{10}$. Dichas actividades igualmente deben someterse a la normativa que se dicte ${ }^{11}$.

\footnotetext{
${ }^{10}$ Puede citarse a modo de ejemplo el caso de lo que se denominan las pisciculturas.

${ }^{11}$ El artículo 90 LGPA señala: "Los establecimientos de cultivos en áreas de propiedad privada, que no requiera de concesión de parte del Ministerio de Defensa Nacional o autorización de la Subsecretaría, estarán obligados a dar cumplimiento a todas las disposiciones reglamentarias que al efecto se dicten".
} 


\section{Derechos constitucionales en que se funda el ejercicio de la actividad de} acuicultura y limitaciones a que se encuentra sometida.

La acuicultura utiliza bienes nacionales, por lo cual requiere el otorgamiento de una concesión de acuicultura especialmente regulada en la LGPA., la que otorga propiedad a su titular sobre el bien incorporal constituido por el derecho de uso y goce exclusivo de un bien nacional de uso público o de un bien fiscal como son los terrenos de playa ${ }^{12}$. En consecuencia, desde el punto de vista constitucional están involucrados en la regulación de la actividad los derechos de los numerales 21, 23 y 24 del artículo 19 CPol., esto es, el derecho a desarrollar cualquier actividad económica lícita, la libertad de acceso a toda clase de bienes y el derecho de propiedad. Además de las facultades legislativas para delimitar derechos y definir los límites a las libertades mencionadas, la potestad estatal de regulación de la actividad está fundada tanto en el deber de tutelar la preservación de la naturaleza contenido en el artículo $19 \mathrm{~N}^{\circ} 8 \mathrm{CPol}$, como en la posibilidad de establecer restricciones específicas a libertades y derechos contenida en el mismo numeral.

a) Derecho a desarrollar cualquier actividad económica (artículo $19 \mathrm{~N}^{\circ} 21$ CPol.). El derecho a desarrollar cualquier actividad económica, reconoce como límites la moral, el orden público y la seguridad nacional, pero somete dicha actividad a las normas legales que la regulen. En principio, parece un mandato al legislador bastante amplio pero no debe olvidarse que toda restricción a un derecho constitucional deberá respetar su contenido esencial (artículo $19 \mathrm{~N}^{\circ} 26 \mathrm{CPol}$.) y fundarse adecuadamente desde el punto de vista de la proporcionalidad (artículo $1^{\circ}$ inciso 4 , artículo $19 \mathrm{~N}^{\circ} 2$ y artículo $20 \mathrm{CPol}$.) puesto que siempre debe existir una finalidad pública involucrada y la medida de restricción debe ser necesaria en el sentido que no exista otra medida menos gravosa con la que se logre el fin;

${ }^{12}$ Concesión de acuicultura es el acto administrativo mediante el cual el Ministerio de Defensa Nacional otorga a una persona los derechos de uso y goce, por el plazo de 25 años renovables sobre determinados bienes nacionales, para que ésta realice en ellos actividades de acuicultura. Artículo $2 \mathrm{~N}^{\circ} 12$ LGPA. Antes de la Ley $\mathrm{N}^{\circ} 20.434$ dictada el 8 de abril del 2010, las concesiones de acuicultura tenían carácter indefinido, sólo sometidas a causales de caducidad. A partir de la modificación legal citada, las concesiones tiene un plazo de duración manteniéndose un doble régimen: las concedidas antes del 8 de abril de 2010 que mantienen su carácter indefinido y las otorgadas con posterioridad a esa fecha que quedaron sometidas a plazo. Sin embargo, la ley previó una norma transitoria para permitir ir llevando al régimen de plazo a todas las concesiones. En efecto, conforme al artículo 15 transitorio de la Ley $\mathrm{N}^{\circ} 20.434$, las concesiones que sean objeto de relocalización conforme al artículo $5^{\circ}$ de la mencionada ley y las aquellas cuyos titulares hubieran accedido a un crédito garantizado por la Corporación de Fomento de la Producción, dentro de los dos años siguientes a la ley, quedarán sometidas a plazo. 
idónea para el cumplimiento del fin; y proporcionada entre la magnitud de la restricción y el fin perseguido ${ }^{13}$.

En consecuencia, la regulación de la actividad económica no debería reemplazar la decisión empresarial en ámbitos que no inciden en la consecución de la finalidad pública definida. ¿Cuál es esa finalidad pública? Si se acude a las normas de la LGPA. se puede encontrar esa finalidad pública en las disposiciones generales y en las específicas del título $6^{\circ}$ referidas a la acuicultura.

Conforme al artículo 1 LGPA., a las disposiciones de esta ley quedará sometida la "preservación de los recursos hidrobiológicos". Por su parte, el artículo $2^{\circ}$ letra p) de la Ley de bases generales del medio ambiente define la preservación de la naturaleza como el conjunto de políticas, planes, programas, normas y acciones, destinadas a asegurar la "mantención de las condiciones que hacen posible la evolución y el desarrollo de las especies y de los ecosistemas del pais". En consecuencia, conforme a este primer objetivo explicitado en la LGPA. debería entenderse que la regulación de la acuicultura alcanzará a todas aquellas acciones que puedan incidir en la mantención de las condiciones que hacen posible la evolución y desarrollo de las especies hidrobiológicas y sus ecosistemas.

Asimismo, con las modificaciones introducidas a la LGPA. por la Ley $\mathrm{N}^{\circ} 20.657$ se agregó el artículo $1 \mathrm{~B}$ que indica que el objetivo de la ley es "la conservación y el uso sustentable de los recursos hidrobiológicos, mediante la aplicación del enfoque precautorio, de un enfoque ecosistémico en la regulación pesquera y la salvaguarda de los ecosistemas marinos en que existan esos recursos.". De esto se deriva que la finalidad pública involucrada en la regulación de las actividades sometidas a la LGPA. es que las actividades sometidas a ella no pongan en riesgo la conservación de los recursos hidrobiológicos y de los ecosistemas en que ellos existen, lo que amplía el ámbito de acción de la Autoridad, dado que no basta considerar, como hasta antes de la modificación de la LGPA., solo el impacto directo sobre los recursos hidrobiológicos sino que deben considerarse además los efectos que dichas actividades producen sobre los ecosistemas en que existen tales recursos.

Por su parte, el título 6 LGPA. contempla objetivos específicos impuestos a la regulación de la acuicultura dirigida a la protección ambiental, a saber:

i) El artículo 74 referido al deber del concesionario de acuicultura de mantener "la limpieza y el equilibrio ecológico de la zona concedida.".

ii) El artículo 86 por el que se deben establecer las medidas para "evitar la introducción de enfermedades de alto riesgo y especies que constituyeran

${ }^{13} \mathrm{El}$ Tribunal Constitucional lo ha aceptado, calificándolo como parte del juicio de razonabilidad, por ejemplo, en la sentencia rol $\mathrm{N}^{\circ} 1535-2009$ (considerando $37^{\circ}$ ). 
plagas, aislar su presencia en caso de que éstas ocurran, evitar su propagación y propender a su erradicación.". 14

iii) El artículo 87 por el que deben establecerse las "medidas de protección del medio ambiente para que los establecimientos que exploten concesiones o autorizaciones de acuicultura operen en niveles compatibles con las capacidades de los cuerpos de agua lacustres, fluviales y maritimos, que aseguren la vida acuática y la prevención del surgimiento de condiciones anaeróbicas en las áreas de impacto de la acuicultura." ${ }^{15}$

De este modo, la regulación de la actividad de acuicultura deberá estar orientada a la consecución de los objetivos indicados, pues configuran la finalidad pública subyacente.

b) Libertad para adquirir el dominio de toda clase de bienes (artículo $19 \mathrm{~N}^{\circ} 23 \mathrm{CPol}$.). La libertad para adquirir el dominio de toda clase de bienes excepto aquellos que la naturaleza ha hecho comunes a todos los hombres o que deban pertenecer a la Nación toda y la ley lo declare así. Además se admite que a través de una ley de quórum calificado y cuando así lo exija el interés nacional, se establezcan limitaciones o requisitos para la adquisición del dominio de ciertos bienes.

Tratándose de las porciones de agua y fondo marino y de las playas, se está en presencia de bienes nacionales de uso público, conforme a los artículos 593 a 595 CC. Debido a que el artículo 595 declara como bienes nacionales de uso público a todas las aguas, en los casos en que la acuicultura suponga la instalación de centros de cultivo en la columna de agua marina, lacustre o fluvial requiere una concesión para su uso exclusivo. En el caso del mar y en el de los lagos y ríos que sean navegables, la competencia para entregar el uso privativo de estos sectores corresponde al Ministerio de Defensa Nacional, que la ejerce a través de la Subsecretaría para las Fuerzas Armadas, de conformidad con el artículo 2 del Decreto con fuerza de ley $\mathrm{N}^{\circ} 340$ de 1960, del Ministerio de Hacienda sobre concesiones marítimas. Al crearse la concesión de acuicultura se mantuvo dicha competencia.

Por su parte, los terrenos de playa fiscales hasta los 80 metros desde la línea de más alta marea medidos desde la costa, también son objeto de concesiones de acuicultura, fundándose la competencia para su otorgamiento en las normas ya citadas.

${ }^{14}$ El resto del artículo no da cuenta de un objetivo sino más bien de medidas concretas y amplió, por efecto de la modificación introducida el año 2010, los sujetos sometidos al reglamento.

${ }^{15}$ La redacción original hasta el año 2010 solo llegaba hasta la frase "aguas lacustres, fluviales y maritimos". Esto es relevante para efectos del alcance que tenía la regulación antes de la gran modificación realizada por efectos de la crisis provocada por la enfermedad que afectó a los salmones denominada ISA. 
Debe aclararse que en los casos en que la acuicultura no se realiza en la columna de agua, esto es, en el caso de centros de cultivo instalados en terrenos privados que utilizan derechos de aprovechamiento de agua, no requieren concesión de acuicultura sino simplemente un registro ante el Servicio Nacional de Pesca para efectos de control y fiscalización de la normativa.

En el caso de los bienes nacionales, sean de uso público o fiscales, no puede adquirirse el dominio de las porciones de mar o de la playa y tampoco de los terrenos de playa fiscales por así disponerlo el artículo 6 inciso $2^{\circ}$ del Decreto-ley $\mathrm{N}^{\circ} 1.939$ de 1977 sobre adquisición, administración y disposición de los bienes del Estado ${ }^{16}$.

Ahora bien la concesión de acuicultura, en cuanto bien incorporal, se constituye en una clase de bien susceptible de propiedad. De allí entonces que se requiera una ley de quórum calificado en los casos que se pretenda restringir, sea por la imposición de limitaciones o requisitos, el acceso a las concesiones de acuicultura.

Dado que la acuicultura utiliza bienes escasos respecto de los cuales el Estado tiene el deber de preservarlos (en general, bienes del borde costero), siempre deberá contemplarse algún régimen de asignación de los derechos para utilizarlos (derechos de uso y goce en los que consiste la concesión de acuicultura), por ende, siempre se requerirá una ley que regule dicha asignación. Se entiende por asignación en este ámbito, el procedimiento al que se somete la decisión en torno a la competencia por un mismo bien y cuyo resultado importa el otorgamiento de un derecho exclusivo para su titular ${ }^{17}$.

Finalmente, la LGPA. realiza una declaración en el artículo 67 bis referido al régimen de los diversos bienes involucrados en la acuicultura que requiere concesión: "Las concesiones y autorizaciones acuicolas no entregan dominio alguno a su titular sobre las aguas ni el fondo marino ubicado en los sectores

${ }^{16}$ La disposición citada indica: "Las tierras fiscales situadas hasta una distancia de 10 kilómetros, medidos desde la frontera, sólo podrán ser obtenidas en propiedad, arrendamiento o a cualquier otro titulo, por personas naturales o juridicas chilenas/Igual norma se aplicará respecto de las tierras fiscales situadas hasta 5 kilómetros de la costa, medidos desde la línea de más alta marea. En este último caso, podrán sin embargo concederse estos beneficios a extranjeros domiciliados en Chile, previo informe favorable de la Subsecretaria de Marina del Ministerio de Defensa Nacional. Con todo no podrán enajenarse a ningún titulo los terrenos de playa fiscales, dentro de una faja de 80 metros de ancho medidos desde la linea de más alta marea de la costa del litoral, los cuales sólo serán susceptibles de actos de administración por parte de la citada Subsecretaria del Ministerio de Defensa Nacional y sujetos a las restricciones establecidas en este articulo".

${ }^{17}$ Durante la tramitación respectiva, tuvieron quórum calificado las disposiciones de las leyes $\mathrm{N}^{\circ} 20.434$ y $\mathrm{N}^{\circ} 20.583$ que cerraron el acceso a nuevas concesiones de Salmónidos en las regiones de Los Lagos y de Aysén y que suspendieron el acceso por un año al mismo tipo de concesiones en la región de Magallanes. 
abarcados por ellas, y sólo les permitirá realizar aquellas actividades para las cuales les han sido otorgadas, de manera armónica y sustentable con otras que se desarrollen en el área comprendida en la respectiva concesión o autorización, tales como la pesca artesanal y el turismo, entre otras".

c) Derecho de propiedad (artículo $19 \mathrm{~N}^{\circ} 24$ CPol.). El derecho de propiedad en sus diversas especies sobre toda clase de bienes corporales e incorporales aparece como relevante desde dos perspectivas: la propiedad de la concesión en cuanto bien incorporal y la propiedad de los ejemplares en cultivo, sea porque el concesionario o cultivador los ha adquirido o producido (importación de ovas o reproducción controlada como en el caso de los salmones) o los ha capturado desde el ambiente natural (captación de semillas de mitílidos ${ }^{18}$.

La Constitución establece que podrán imponerse a la propiedad las limitaciones y obligaciones que se derivan de su función social, basada en la conservación del patrimonio ambiental. Precisamente a este tema se abocará el análisis de la evolución de la normativa ambiental aplicable a la acuicultura, sus alcances y estado actual, cuyo marco está dado principalmente por la LGPA. y la LBGMA., y la reglamentación correspondiente a ambos cuerpos legales.

d) Deber de tutelar la preservación de la naturaleza. Aparece como fundamental el deber del Estado del artículo $19 \mathrm{~N}^{\circ} 8 \mathrm{CPol}$. en orden a tutelar la preservación de la naturaleza así como el derecho que puede ser invocado por los particulares en cuanto se afecte el derecho a vivir en un medio ambiente libre de contaminación. El alcance que el legislador le da a este deber en la LGPA fue planteado más arriba. al revisar los objetivos que se incorporan en la regulación.

En este sentido, es relevante destacar el inciso $2^{\circ}$ del artículo $19 \mathrm{~N}^{\circ} 8$ CPol. que prescribe: "la ley puede establecer restricciones especificas al ejercicio de determinados derechos o libertades para proteger el medio ambiente".

Así las cosas, puede afirmarse que para dar cumplimiento al deber preservar la naturaleza y resguardar el derecho a vivir en un medio ambiente libre de contaminación, el constituyente previó la posibilidad de establecer restricciones específicas a determinados derechos y libertades. Las principales restricciones están dadas por las disposiciones de la LBGMA. y la LGPA, en

\footnotetext{
${ }^{18}$ Esto implica que las semillas de mitílidos se adquieren por ocupación, ya que se trata de una actividad extractiva pero la LGPA. no exige registrarse como pescador artesanal para ejercer esta actividad (no podría otorgarse autorización de pesca industrial ya que dicha actividad se realiza dentro del área de reserva artesanal establecida en el artículo 47 LGPA.). La ley exige realizar esta actividad en una concesión de acuicultura, en áreas de manejo o a través de autorizaciones especiales para la instalación de colectores.
} 
materia de acceso a las concesiones y de las condiciones bajo las cuales puede desarrollarse esta actividad económica.

e) Igualdad ante la ley y la no discriminación arbitraria en el trato que debe dar el Estado y sus organismos en materia económica (artículo 19 Nos. 2 y 22 CPol.). Las garantías de los Nos. 2 y 22 del artículo $19 \mathrm{CPol}$. imponen al Estado el respeto de la igualdad ante la ley y la prohibición de la discriminación arbitraria en el trato que dar el Estado y sus organismos en materia económica. Esto es relevante, atendida la amplia actividad que el Estado despliega en materia de regulación, fiscalización y sanción de quienes ejercen la actividad de la acuicultura.

Por su parte estas garantías adquieren mayor relevancia al considerar la nueva normativa incorporada a la LGPA. y sus reglamentos a partir del año 2008 , que comprende regulaciones que imponen un comportamiento coordinado obligatorio a los productores, en donde la actuación de un cultivador puede traer consecuencias a sus vecinos que se traducen en sanciones, como se verá más abajo. con las disposiciones referidas a descansos coordinados, planes de manejo y densidad de cultivo de las agrupaciones de concesiones. De este modo, resulta esencial evaluar la actuación estatal bajo el parámetro de control de la igualdad ante la ley y de la no discriminación arbitraria en materia económica, ya que aquella puede incidir directamente en el comportamiento de actores que si bien comparten el mismo ambiente marino, son competidores en la actividad económica. Así el Estado debe siempre fundar su actuación sólo en la finalidad pública de la conservación ambiental, a fin de evitar que se introduzcan distorsiones ilegítimas en la competencia.

\section{EvOlUCiÓN DE LA NORMATIVA AMBIENTAL}

APLICABLE A LA ACUICULTURA

En la evolución de la normativa ambiental aplicable a la acuicultura pueden distinguirse cuatro períodos marcados por cambios sustantivos experimentados por la regulación: i) Período 1989 a 2001, que va desde la primera norma ambiental dictada para la acuicultura originada en la modificación del Decreto supremo $N^{\circ} 175$ de 1980 del Ministerio de Economía, Fomento y Turismo y que culmina con la dictación de los reglamentos que ordena la LGPA., modificada en el 1991 en materia de acuicultura. Tales reglamentos se refieren a la importación de especies hidrobiológicas, sanitario, ambiental y de plagas. Asimismo en este período empieza la aplicación del sistema de evaluación de impacto ambiental; ii) Período 2002 a 2007: período de implementación de la nueva normativa sectorial y consolidación del sistema de evaluación de impacto ambiental como procedimiento de evaluación ambiental. Fue emitida una la "Política Nacional de Acuicultu- 
ra" de acotado impacto como instrumento directivo para la autoridad y el sector privado. Este período culmina con el inicio del brote del virus Isa que afecta a la salmonicultura y que importó profundos cambios en la normativa ambiental aplicable a la acuicultura; iii) Período 2008 a 2010: época de crisis para la industria salmonera, la de mayor tamaño en Chile y que importó la necesidad de adoptar rápidas medidas de emergencia que aparecían como recomendables, muchas de las cuales debieron fundarse en facultades generales de la Autoridad y otras debieron esperar la modificación de los reglamentos; y iv) Período 2010 a la fecha: se publica el 8 de abril de 2010 la ley 20.434 que modifica la normativa referida a la acuicultura en forma sustantiva y que requirió de una implementación a través de la dictación de una serie de reglamentos que recién terminó de completarse con la implementación del reglamento de densidades de cultivo a partir de enero de 2014.

A fin de comprender adecuadamente la evolución de la normativa y su impacto se abordará la caracterización de la normativa de cada uno de los períodos enunciados ${ }^{19}$.

\section{Periodo 1989 a 2001.}

Antes del año 1991 en que se dictó la Ley N ${ }^{\circ} 19.079$ con que fue modificada la LGPA. introduciendo una normativa específica referida a la acuicultura, sólo se aplicaban a la actividad existente y en incipiente desarrollo a esa fecha, el Decreto supremo $N^{\circ} 175$ de 1980 del Ministerio de Economía, modificado por el Decreto supremo $\mathrm{N}^{\circ} 427$ de 1989 del mismo ministerio, que contemplaba las siguientes medidas:

i) En los cultivos de salmónidos, debía mantenerse una distancia de separación entre centros de cultivo de 1,5 millas náuticas, salvo en el caso que existiera un accidente geográfico que interrumpiera la línea imaginaria que debía trazarse entre los vértices de las concesiones para determinar dicha distancia. En estos últimos casos, igualmente no podían autorizarse los centros en sectores con profundidades inferiores a 25 metros ni corrientes de valores inferiores a $2,5 \mathrm{~cm} / \mathrm{seg}$.

ii) En los cultivos de salmónidos en cuerpos lacustres solo podían autorizarse los centros hasta alcanzar en cada cuerpo un nivel de producción conjunta máxima, expresado en toneladas, equivalente a dividir por 35 la extensión total del lago, medida en hectáreas ${ }^{20}$.

iii) Las solicitudes para operar centros de cultivo de salmónidos en aguas

${ }^{19}$ Lo relevante en el presente artículo es dar cuenta acerca de la forma como la normativa ambiental aplicable a la acuicultura ha sido instaurada y ha ido cambiando en el tiempo. De allí que se aborde desde la perspectiva de su evolución.

${ }^{20}$ Estas solicitudes debían observar una serie de condiciones técnicas relativas a distancias, velocidad de corrientes, peso de los ejemplares, entre otras. 
fluviales, se autorizarían hasta alcanzar en cada sistema fluvial una producción conjunta máxima, expresada en toneladas, equivalente a dividir por $25 \mathrm{el}$ caudal mínimo, medido en lt/seg (litros por segundo), en época de estiaje, los caudales se calcularían sobre la base de un promedio de caudales mínimos para un período de 15 años, preferentemente ${ }^{21}$.

Las medidas ambientales aplicadas en este período solo se establecieron para el cultivo de salmónidos: distancias entre centros de cultivo, profundidades y velocidades de corriente mínimas, una capacidad máxima de producción determinada conforme a una fórmula para aguas lacustres y fluviales, distancia de las estructuras de cultivo con el fondo marino y la necesidad de contar con un sistema de retención de al menos el 85\% de los sólidos en suspensión en aguas lacustres y fluviales. Es destacable que ya en 1989 se instauraran medidas que hoy aparecen como estructurales a la normativa ambiental de la acuicultura y que por mucho tiempo, al menos una de ellas como es la capacidad máxima de producción, fuera simplemente postergada.

Este período estuvo caracterizado por la implementación de la Ley $\mathrm{N}^{\circ}$ 19.079 de 1991 que al modificar la LGPA para establecer un estatuto específico para la acuicultura, tuvo por principal objetivo la promoción de la actividad, lo que se tradujo en la dictación de áreas apropiadas para la acuicultura y en la progresiva entrega de concesiones de acuicultura, tendencia que se vio fuertemente incrementada en el período 1996-2005.

Desde el punto de vista ambiental, no se plasmó la preocupación del legislador en una oportuna actividad del Administrador y por ello se produjo un crecimiento sostenido de la actividad bastante inorgánico y con normas mínimas que eran poco adecuadas para resguardar su sustentabilidad.

i) Los artículos 11 y siguientes de la LGPA. referidos a la importación de especies hidrobiológicas. Dos reglamentos fueron establecidos al efecto: el de la certificación para la importación habitual y el reglamento de primera importación de especies hidrobiológicas. Estas normas son relevantes para efectos de evitar la introducción de enfermedades no presentes en el país a través de los ejemplares que ingresan al territorio nacional y para evaluar

${ }^{21}$ Las solicitudes debían observar las siguientes condiciones técnicas: i. una distancia mínima de separación entre ellos de 3 kilómetros la que se mediría siguiendo el eje principal del río, desde los lugares de descarga de las aguas efluentes de un establecimiento y hasta las áreas de captación del establecimiento más cercano ubicado aguas arriba y abajo; ii. cada establecimiento ubicado en cursos fluviales debía contar con un sistema de decantación para las aguas efluentes, diseñado para la decantación de al menos un $85 \%$ de los sólidos en suspensión producidos por el establecimiento de cultivo. Además se debía utilizar, en las mismas aguas efluentes, sustancias naturales tampones que neutralizaran el amonio y se recuperen los niveles de $\mathrm{pH}$ y oxígeno originales. 
preventivamente posibles impactos de nuevas especies exóticas que pretenden ser introducidas para al cultivo.

ii) Los artículos del Decreto supremo citados más arriba que fundaron la emisión del Reglamento ambiental para la acuicultura (= RAMA.).

iii) El artículo 86 citado precedentemente, que fundó la dictación del denominado Reglamento sanitario (RESA.)

En el año 1995 se dictó el reglamento de primera importación de especies hidrobiológicas (fundado en los artículos 12 y 13 LGPA.) ${ }^{22}$ y recién en el año 2001 se libró tres reglamentos: el Decreto Exento Nº 626 de 2001, del Ministerio de Economía, que estableció el reglamento de importación habitual de especies hidrobiológicas (fundado en el artículo 11 LGPA.); el Decreto supremo $\mathrm{N}^{\circ} 319$ de 2001 del mismo ministerio que estableció el denominado RESA. (fundado en el artículo 86 LGPA. antes mencionado) y el Decreto supremo $\mathrm{N}^{\circ} 320$ del mismo año y ministerio, denominado RAMA. (basado en los artículos 74 y 87 LGPA. ${ }^{23}$. En el año 2006 se modificó la LGPA. para instaurar la necesidad de regular la investigación, cultivo, comercialización e importación de organismos genéticamente modificados. Dicho reglamento no ha sido emitido a la fecha.

Por otra parte, en este período entran en vigencia dos normativas de

${ }^{22}$ Decreto supremo $\mathrm{N}^{\circ} 730$ de 1995 del Ministerio de Economía, Fomento y Turismo. La importación habitual se refiere a las especies hidrobiológicas que ya han ingresado al país y respecto de las cuales se hacen exigencias de certificación sanitaria por el país de origen para el ingreso. Dichas especies están en una nómina dictada por la Subsecretaría de Pesca denominada de importación habitual. Por su parte, la primera importación se refiere a aquellas especies hidrobiológicas que no se encuentran naturalmente en el territorio nacional y que no han sido importadas o que habiéndolo sido, se encuentran en un régimen de experimentación previo a su incorporación en la nómina de especies hidrobiológicas que son de importación habitual

${ }^{23} \mathrm{La}$ importación de especies hidrobiológicas está tratada en los artículos 11 ss. LGPA. pese a que está relacionada con la introducción de enfermedades de alto riesgo por lo cual sus disposiciones complementan las del RESA. En el año 2001 se dictó el Decreto exento $\mathrm{N}^{\circ} 626$ del Ministerio de Economía, Fomento y Turismo que estableció el primer reglamento en la materia, el que fue derogado por el Decreto supremo $\mathrm{N}^{\circ}$ 72 de 2011 del mismo Ministerio. Es de destacar que el primer reglamento fue emitido como exento debido a que la LGPA. indica que dicha normativa debe dictarse por decreto por orden del presidente de la República y la Contraloría General de la República solicitó en su oportunidad el retiro del anterior decreto en trámite (Decreto supremo $\mathrm{N}^{\circ} 325$ de 1999 del Ministerio de Economía, Fomento y Turismo) por considerar que debía seguirse el mandato del artículo 11 LGPA., sin pronunciarse acerca de la aplicación de la doctrina del Tribunal Constitucional acerca de la necesaria firma del presidente de la República respecto de todos los reglamentos por mandato del artículo 35 CPol. Cuando se tramitó el reglamento en el año 2011 no hubo cuestionamiento al carácter de Decreto Supremo que debía revestir dicho reglamento. 
carácter general que serán de aplicación a la acuicultura: la nueva legislación ambiental, la Ley $\mathrm{N}^{\circ} 19.300$ LBGMA. y el reglamento del sistema de evaluación de impacto ambiental, y la "Política Nacional de Uso del Borde Costero" establecida por Decreto supremo N 475 de 1994 del Ministerio de Defensa Nacional.

a) $L B G M A$. Si bien la ley 19.300 data de 1994 , en lo que interesa al presente artículo, la legislación ambiental pertinente empieza a regir el 3 de abril de 1997 cuando se publica el reglamento del sistema de evaluación de impacto ambiental. La acuicultura es una de aquellas actividades que queda sometida al sistema, existiendo en el artículo 87 de la LGPA un permiso ambiental sectorial que debía emitir la Subsecretaria de Pesca a través del sistema de evaluación de impacto ambiental. Previo al análisis deben hacerse dos comentarios.

En primer lugar, no existía a esta fecha, el RAMA. que exigía la LGPA. en su artículo 87, por ende, las evaluaciones ambientales se realizaban conforme a las disposiciones del Decreto supremo $\mathrm{N}^{\circ} 175$ de 1989 del Ministerio de Economía y se comenzaron progresivamente a incorporar en la evaluación ambiental elementos que no tenían un fundamento explícito en la normativa sino más bien se sustentaban en las normas generales establecidas en la LGPA.: la obligación de mantener la limpieza y el equilibrio ecológico de la zona concedida (artículo 74 de la LGPA.) y el deber de operar conforme a las capacidades de los cuerpos de agua, pese a que como ya se dijo, no estaban dictadas las mencionadas condiciones.

En segundo lugar, se interpretó por parte de los órganos intervinientes en el otorgamiento de la concesión de acuicultura, que la obligación de someterse al sistema de evaluación de impacto ambiental. era aplicable a las nuevas solicitudes que se presentaran a tramitación a partir del 3 de abril de 1997, pero no así a las solicitudes que se encontraban en trámite. Así las cosas, entre el 3 de abril de 1997 y el 18 de junio de $2001^{24}$ se otorgaron concesiones que no se sometieron al sistema de evaluación de impacto ambiental.

En cuanto al sometimiento al sistema de evaluación de impacto ambiental., si bien en un principio todos los proyectos, independiente de su magnitud, se sometían al sistema conforme al artículo 10 letra n) de la ley 19.300, a partir de la modificación del reglamento del sistema de evaluación

${ }^{24}$ Fecha en que se notifica a la Subsecretaría de Pesca el Dictamen N 21270 de 6 de junio de 2001 de la Contraloría General de la República que atiende un requerimiento de un grupo de diputados quienes discuten la interpretación aplicada a esa fecha al sometimiento al sistema de evaluación de impacto ambiental a los centros de cultivo. Contraloría cambia entonces la interpretación y determina la aplicación de la normativa vigente a toda solicitud pendiente, independientemente de la fecha de ingreso a tramitación. 
de impacto ambiental. efectuada el año 2001, se establecen umbrales de sometimiento, de modo que los proyectos que no alcanzan dichos umbrales no se someten al sistema y son evaluados ambientalmente a nivel sectorial por la Subsecretaría de Pesca ${ }^{25}$.

b) "Politica Nacional de Uso del Borde Costero". Definida como un política de Estado, nacional, sistémica, multidisciplinaria que tiene por objetivos, entre otros, propender al desarrollo de los recursos y riquezas de los distintos sectores del borde costero, la protección y conservación del medio ambiente marítimo, terrestre y aéreo, acorde con las necesidades de desarrollo y a una adecuada compatibilización de las múltiples actividades que se realizan o puedan realizarse en el borde costero así como posibilitar y orientar el desarrollo equilibrado de las diferentes actividades, desde una perspectiva nacional, acorde con los intereses regionales, locales y sectoriales ${ }^{26}$.

A partir de dicha política se creó la Comisión Nacional de Uso del Borde Costero, integrada por representantes de diversos Ministerios con incidencia en dicha área y se llamó a las Autoridades regionales a proponer la zonificación del borde costero regional, de modo de instaurar instrumentos que permitieran al Ministerio de Defensa Nacional, a través de la Subsecretaría de Marina, hoy Subsecretaría para las Fuerzas Armadas, adoptar las decisiones sobre las solicitudes de concesiones marítimas y de acuicultura fundadas en las definiciones regionales acerca de los usos que se emplazarían en las diversas áreas del borde costero regional. Así se pretendía instaurar un instrumento directivo de las decisiones de la autoridad sobre el espacio costero.

\section{Periodo 2002-2007.}

Con la entrada en vigencia del RAMA. en enero de 2002 comienzan a aplicarse sus disposiciones a la evaluación ambiental, pese a que la resolución acompañante del mismo que especifica las metodologías y procedimientos se dicta recién en $2003^{27}$.

En este período no se considera el RESA. como normativa ambiental aplicable al proyecto por lo cual las evaluaciones ambientales no lo contemplan ni incluyen dentro de las resoluciones de calificación ambiental. Esto empezará a cambiar con la crisis que se produce en el año 2007 por el brote del virus Isa que afectó la producción de salmones, particularmente al Salmón del Atlántico.

En los primeros dos años de este período se llevó a cabo la implementación

${ }^{25}$ Artículo 3 letra n) del Reglamento del sistema de evaluación de impacto ambiental, contenido en el Decreto Supremo N ${ }^{\circ} 40$ de 2012, del Ministerio del Medio Ambiente.

${ }^{26}$ Artículo $1^{\circ}$ numeral III del Decreto supremo $N^{\circ} 475$ de 1994 del Ministerio de Defensa Nacional.

${ }^{27}$ Resolución $N^{\circ} 404$ de 2003 de la Subsecretaría de Pesca. 
del RESA. y RAMA., siendo fundamentales las disposiciones que decían relación con el ajuste de los centros en operación a las nuevas exigencias y la imposición de las condiciones de acceso a las solicitudes de concesión que estaban en trámite.

Estos reglamentos pueden caracterizarse por lo siguiente:

a) No establecer medidas preventivas de resguardo ambiental sino condiciones de acceso y operación mínimas. Cabe destacar la oposición que la industria manifestó en la discusión de los reglamentos los que requerían de informes del Consejo Nacional de Pesca ${ }^{28}$ sin los cuales no podían ser tramitados y, por ende, los actores tenían una instancia de oposición formal para evitar la dictación de la normativa.

b) Los reglamentos establecen condiciones a cumplir dejando a resoluciones del Servicio Nacional de Pesca (RESA.) y de la Subsecretaría de Pesca (RAMA.) la especificación de las metodologías y procedimientos específicos de aplicación (programas sanitarios en el caso del RESA y resolución acompañante en el caso del RAMA.). Dichas resoluciones no están sometidas al control de la Contraloría General de la República, la que validó la remisión a dichas resoluciones.

Esto se debe a la complejidad, detalle y rápida evolución de las técnicas de cultivo, técnicas de diagnóstico de las enfermedades y de la tecnología aplicada a ambas actividades, lo que impone la necesidad de realizar rápidos ajustes que faciliten un mejor control y mayor flexibilidad de adecuación a los cambios.

Teniendo en consideración que dichas disposiciones tienen un carácter general y que son de aplicación directa a los particulares y no de aplicación interna a los órganos del Estado, aparece como una resolución de carácter reglamentario muy útil por su flexibilidad pero difícil de ubicar dentro de la jerarquía de normas del ordenamiento jurídico nacional ${ }^{29}$.

Así las cosas, el control de legalidad del actuar del órgano que dicta la resolución es eventual a través de su impugnación administrativa o judicial.

c) La configuración y sanción reiterada por infracciones a cualquiera de

${ }^{28}$ Instancia de composición público-privada donde estaban representados los actores de la actividad de la pesca y la acuicultura, la que debía aprobar o informar determinadas medidas propuestas por la autoridad, sin la cual no podían ser implementadas.

${ }^{29}$ En el caso de la píldora del día después, el Tribunal Constitucional en su fallo rol N 591 de 2007 determinó que la política de fertilidad regulada por una resolución exenta incidía en derechos constitucionales y tenía carácter reglamentario y, por ende, debía dictarse mediante un decreto supremo reglamentario. Si se considera que la resolución acompañante del RAMA. solo especifica metodologías y procedimientos ya ordenados por el propio reglamento, no se configura la misma situación, dado que las medidas están contempladas en el reglamento. 
estos reglamentos impone la caducidad de la concesión, lo que se ve morigerado por el procedimiento judicial civil a que se ven sometidas las infracciones de la LGPA. que importan una demora que al menos en esta época hacían poco probable la configuración de la causal de caducidad respectiva ${ }^{30}$. Puede apreciarse entonces una clara vinculación entre el título concesional y la mantención de las condiciones incorporadas al mismo como es el cumplimiento de la normativa ambiental.

En lo particular, el RESA establecía:

i) La facultad para fijar anualmente una clasificación de las enfermedades de alto riesgo en lista 1 y 2 , conforme a las cuales se exigía la certificación sanitaria a la importación de especies hidrobiológicas para prevenir enfermedades. Dicha normativa fue un avance pero no incorporó restricciones sustantivas que aseguraran que se evitara el ingreso de nuevas enfermedades.

ii) La facultad del Servicio Nacional de Pesca para que a través de resoluciones dictara programas sanitarios generales que establecían los requisitos que debían cumplirse en los procedimientos rutinarios del centro de cultivo para mantener condiciones sanitarias adecuadas. También era posible dictar programas sanitarios específicos para el monitoreo y control de enfermedades y debiendo dictarse en el plazo de dos años los programas para las enfermedades de alto riesgo de Lista 2 (presentes en Chile). Dichos programas no se dictaron sino a partir de la crisis del virus ISA de 2007.

iii) La facultad del Servicio Nacional de Pesca para establecer una zonificación del territorio nacional en base a su estatus sanitario. Para ello se requiere realizar una vigilancia mediante un sistema periódico y sostenido de muestreos a los ejemplares en cultivo. No existió zonificación sanitaria sino hasta la aparición del brote de Isa en el año 2008.

iv) Un elemento sustantivo fue la facultad el Servicio Nacional de Pesca de ordenar la eliminación de los ejemplares en cultivo o su completa destrucción ante un evento de emergencia sanitaria (artículos 6 y 7 RESA.). Esta norma establecida en el reglamento se fundaba en la declaración genérica del artículo 86 de la LGPA que indicaba que se establecerían las medidas para evitar la introducción de enfermedades de alto riesgo, para aislar su presencia en caso que ocurrieran, para controlarlas y para propender a su erradicación.

La legalidad de la facultad era discutible dado que se trataba de una limitación a la propiedad (propiedad sobre los ejemplares en cultivo) que debía ser establecida por ley por aplicación expresa del inciso $2^{\circ}$ del numeral 24 del artículo 19 CPol.. Sin embargo, se acogió la tesis según la cual la referencia genérica contenida en el artículo $86 \mathrm{CPol}$. resultaba suficiente al efecto, puesto que era la LGPA la que determinaba la necesidad de adoptar medidas.

${ }^{30}$ Artículo 142 letra c) LGPA. 
v) Otros elementos incorporados al reglamento era la regulación de los laboratorios de diagnóstico de enfermedades de especies hidrobiológicas y los laboratorios de referencia así como la necesidad de contar con prescripción médico veterinaria para el uso de tratamientos terapéuticos que debían estar registrados. Cabe destacar que los laboratorios de referencia no fueron instaurados sino con posterioridad a la crisis sanitaria de 2007.

vi) Al RESA. no se incorporaban límites de aceptabilidad que midieran indicadores que dieran cuenta del comportamiento sanitario, lo que tendría serias consecuencias con posterioridad. Por ejemplo, se consideraba la densidad de cultivo (número de peces por $\mathrm{m}^{3}$ de la jaula de cultivo) era una decisión empresarial sin posibilidad de ser intervenida por la Autoridad. Sin embargo, una alta cantidad de peces en una misma jaula propicia los brotes de enfermedades y su diseminación.

Por su parte, el RAMA incorporó:

i) A diferencia del período anterior, condiciones ambientales para el ejercicio de la actividad de acuicultura para todos los cultivos. En efecto, el RAMA. introdujo distancias para todos los cultivos, salvo las algas, manteniendo en 1,5 millas (2.778 metros) la distancia entre centros de cultivo intensivo (aquéllos que suponen la entrega de alimento a los ejemplares en cultivo y, por ende, incluye a los salmones y en general a todos los peces); 200 metros entre centros de cultivo extensivos (aquellos que no alimentan artificialmente sino que suponen la alimentación natural desde el medio como los mitílidos); y 400 metros entre centros intensivos que se alimenten exclusivamente de algas y los centros de cultivo extensivo (caso del abalón).

ii) Instrumentos de evaluación ambiental específicos para la actividad: la caracterización preliminar del sitio (CPS) y los informes ambientales. La CPS tiene por objetivo determinar las condiciones del sitio en que se proyecta la realización de la actividad e impone realizar una descripción del sector basada en muestreos, que permita una evaluación previa al otorgamiento de la concesión. Esta CPS se solicita en el sometimiento al sistema de evaluación de impacto ambiental. Por su parte, un informe ambiental debe ser periódicamente presentado por el titular de la concesión para dar cuenta de la situación de aerobiosis en el sitio en cultivo (oxígeno en el fondo o en la columna de agua) que fue el indicador definido para acreditar que se está operando conforme a las capacidades de los cuerpos de agua.

Tanto la CPS como los informes ambientales eran elaborados por el concesionario con la asesoría de un profesional en la materia, lo que fue objeto de grandes críticas cuando se detectaron casos en que dichos instrumentos resultaron no ser fidedignos, puesto que de ellos dependía tanto la autorización ambiental de la actividad como el mantenimiento en operación. Dicho de otro modo, el cumplimiento de la condición de acceso y mantenimiento 
en la operación del centro de cultivo dependía de lo que arrojase el informe de un asesor contratado por la misma empresa sometida a control.

iii) Límite de aceptabilidad: la aerobiosis o existencia de oxígeno en el fondo o en la columna de agua, esto es, la presencia de oxígeno daba cuenta que el centro de cultivo estaba operando en niveles compatibles con las capacidades del cuerpo de agua en que se encontraba. Verificada la condición de anaerobiosis (no existencia de oxígeno), podía continuarse la operación por un año más pero ante una nueva condición de anaerobiosis debía rebajarse en un $30 \%$ el número de ejemplares a cultivar ${ }^{31}$. Esto es lo que justifica que se indique abiertamente que este reglamento no tenía un carácter preventivo.

iv) Plan de contingencia que es un instrumento que debe elaborar el titular del centro de cultivo y sometido al Servicio Nacional de Pesca el que debe dar cuenta de las acciones a desplegar en el caso de producirse un evento indeseado, siendo el de mayor preocupación, los escapes de peces o el desprendimiento de especies exóticas en cultivo, por el impacto que dichos ejemplares pueden provocar en la fauna nativa.

En particular, los escapes de peces han planteado en el tiempo la pregunta acerca de la posibilidad de captura de dichos peces por terceros, ya que son de propiedad del titular del centro de cultivo. En estos casos el artículo 611 CC. dice que la caza marítima y la pesca se regularán por las disposiciones del Código y, preferentemente, por la legislación especial que rija al efecto.

El artículo 607 CC. señala que la caza y la pesca son especies de ocupación por las cuales se adquiere el dominio de animales bravíos y a su vez, los animales bravíos conforme al artículo 608 CC. señala que son aquellos que viven naturalmente libres e independientes del hombre, y son domesticados los que siendo bravíos por su naturaleza se han acostumbrado a la domesticidad y reconocen en cierto modo el imperio del hombre. Sin embargo, estos animales mientras conservan la costumbre de volver al amparo o dependencia del hombre, siguen la regla de los animales domésticos, y perdiendo esta costumbre vuelven a la clase de los animales bravíos. Por este motivo, los peces son animales bravíos. De acuerdo al artículo 611 CC., la caza marítima y la pesca se regularán por las disposiciones del mismo y, preferentemente, por la legislación especial que rija al efecto.

En consecuencia, para que opere la ocupación de los peces escapados debe estarse preferentemente a las normas de la LGPA. Dicha normativa impone al titular del centro de cultivo la recaptura de los ejemplares escapados por un período de 10 días prorrogables por igual plazo. De esta forma, podría sostenerse que mientras esté pendiente la recaptura, nadie más que el titular puede capturar los ejemplares escapados. La pregunta que surge es ¿qué pasa

\footnotetext{
${ }^{31}$ Artículo 20 RAMA en su versión original.
} 
cuando se vence el plazo o los ejemplares exceden la distancia? ¿Pueden ser capturados por terceros? ¿Cómo aplica la LGPA. para estos casos? Porque en el caso de la pesca artesanal su ejercicio requiere tener la especie hidrobiológica inscrita en el registro pesquero artesanal que lleva el Servicio Nacional de Pesca. El tema se ha planteado respecto de los salmones los que no son inscritos en el registro por no constituir una pesquería (son especies exóticas introducidas en cuerpos y cursos de agua del territorio nacional).

En este punto y a falta de norma expresa en la LGPA., debería volverse a las normas del código Civil en los casos de escapes y así la captura de ejemplares escapados estaría validada por la ocupación como modo de adquirir y solo bajo las condiciones antes señaladas (vencimiento del plazo de recaptura). El problema que presenta esta solución es más práctico que jurídico porque allí simplemente se entiende que tal solución constituiría un incentivo la ruptura de las redes en que están confinados los salmones para facilitar su robo.

v) Condiciones de operación como evitar vertimientos, la necesidad de mantener la limpieza de las playas y los terrenos de playa aledaños a la concesión, entre otras (artículo $4^{\circ}$ ).

En este período además se completó la dictación de la normativa ordenada por la LGPA dictándose el reglamento que establece las condiciones para evitar la introducción de plagas, aislar su presencia en caso que ocurran, controlarlas y propender a su erradicación o también conocido como REPLA. ${ }^{32}$ y que tiene mayor relevancia para el cultivo de mitílidos debido a que las plagas más importantes que afectan a la actividad son las denominadas floraciones algales nocivas, más conocidas como marea roja y que importan restricciones de cosecha y de transporte en los períodos en que se presentan.

Desde el punto de vista del sector pesquero, en este período por primera vez se dicta una política para orientar las decisiones de la Autoridad y de los privados. Así mediante el Decreto supremo $\mathrm{N}^{\circ} 125$ de 2003 se dictó la "Política Nacional de Acuicultura" ${ }^{3}$. La Política contemplaba como objetivo "promover el máximo nivel posible de crecimiento económico de la acuicultura chilena en el tiempo, en un marco de sustentabilidad ambiental y equidad en el

${ }^{32}$ Decreto supremo $\mathrm{N}^{\circ} 345$ de 2005 del Ministerio de Economía, Fomento y Turismo.

${ }^{33}$ Además se crea la Comisión Nacional de Acuicultura como instancia de colaboración público-privada que pretendía generar una instancia de discusión específica para la actividad de la acuicultura, y cuyo fin último era reemplazar al Consejo Nacional de Pesca en esta labor por cuanto no se reflejaban en dicho consejo adecuadamente los intereses de los cultivadores por tener una composición mayoritariamente pesquera. Sin embargo, la LGPA no fue modificada en este aspecto sino hasta el año 2012 en que se dicta la Ley $\mathrm{N}^{\circ} 20.597$ que crea por ley la Comisión Nacional de Acuicultura otorgándole facultades consultivas y elimina los temas de acuicultura del ámbito de pronunciamiento del Consejo Nacional de Pesca. 
acceso a la actividad". A partir de dicho objetivo se plantean políticas asociadas al crecimiento económico, a la sustentabilidad ambiental, a la protección del patrimonio sanitario, a la equidad, a la institucionalidad pública y el marco jurídico-legal y a la investigación y capacitación.

Es interesante el diagnóstico que se realiza a la fecha de su dictación (2003) y que da cuenta de las estrategias y de las grandes líneas de acción en las que debería ponerse el énfasis desde la perspectiva pública y privada para asegurar un crecimiento sostenido y sustentable de la actividad. Lamentablemente dicha política quedó como una predicción de los problemas que podrían presentarse pero no tuvo el impacto de generar los cambios normativos y de prácticas ambientales y sanitarias que evitaran la profunda crisis iniciada en el año 2007 y que culminó con un cambio profundo en las bases sobre las que debía asentarse el ejercicio de la actividad.

Finalmente, en este período aparece el primer instrumento de zonificación regional del borde costero aprobado por la región de Aysén y luego por la Comisión Nacional de Uso del Borde Costero que establecía los usos preferentes para dicho borde costero. Se levantó como un instrumento de macro-zonificación, esto es, se realizan definiciones de uso preferente que abarcan amplias zonas del territorio regional indicándose que con posterioridad se entraría a un proceso de microzonificación mediante el cual se definirían, dentro de cada zona, especificaciones que dieran mayor flexibilidad a los usos que no habían resultado ser considerados preferentes en ellas.

Dicha zonificación apareció como una reacción a la gran cantidad de solicitudes de concesiones de acuicultura de salmones en la región de Aysén, en un momento que la industria había ampliado sus proyecciones de crecimiento y decidió trasladarse a dicha región. De este modo, los demás actores del borde costero como el sector turismo, la pesca artesanal y los movimientos y ONGs ambientalistas, así como amplios sectores de la comunidad local plantearon una fuerte oposición a su llegada y la zonificación fue el procedimiento a través del cual canalizar dicha preocupación y demanda de ordenamiento. Claramente la experiencia de un crecimiento inorgánico en la región de Los Lagos, con un progresivo nivel de conflicto incidió en este planteamiento.

El problema que se suscitó durante la discusión fue que las áreas apropiadas para la acuicultura indicaban dónde se podían solicitar concesiones de acuicultura, encontrándose establecidas en el artículo 67 LGPA. Asimismo, las causales de rechazo de las concesiones son de derecho estricto y, por ende, la zonificación no aparecía como un fundamento legal válido para su aplicación directa en el procedimiento de otorgamiento de la concesión. Por su parte, la zonificación del borde costero tenía como sustento normativo la "Política Nacional de Uso del Borde Costero", el que era un instrumento 
directivo que no constituía normativa aplicable a las solicitudes de concesiones de acuicultura.

De esta forma, una vez aprobada la zonificación por Decreto supremo $\mathrm{N}^{\circ} 153$ de 2004 del Ministerio de Defensa Nacional se planteó el problema acerca de por qué vía hacerlo aplicable, ya no como instrumento meramente directivo sino como norma a cumplir y que permitiera imponer condiciones o denegar en los casos en que se así se dispusiera por la zonificación.

En efecto, la zonificación establecía como regla general zonas de uso preferente, esto es, se definía un amplio sector donde tendría primacía un determinado uso por sobre otros. Los usos no preferentes debían someterse en dichas zonas a condiciones de acceso y de operación especificadas en la zonificación. Así por ejemplo, en el caso del uso preferente para el turismo, no podían instalarse centros de cultivo a menos de 3 kilómetros de la desembocadura de ríos de relevancia para el turismo. También se contemplaban pero en menor medida, áreas de uso incompatible, donde simplemente se excluían determinados usos. Por ejemplo, en áreas de preservación no podía realizarse acuicultura.

Finalmente, la zonificación comenzó a ser aplicada a través del sistema de evaluación de impacto ambiental. por cuanto este último incluye el uso territorial como un elemento a evaluar. Las áreas de uso incompatible presentaban una menor complejidad de aplicación por los efectos específicos en que ellos consisten y donde el fundamento de la incompatibilidad de uso suele ser sólido. Sin embargo, la dificultad empezó a presentarse con las áreas preferentes debido a que no siempre era posible exigir en el sistema de evaluación de impacto ambiental las condiciones que habían sido fijadas para ellas.

\section{Periodo 2008-2010 34 .}

El 1 de julio de 2007 se comunicó a la autoridad el primer brote de Isa, enfermedad que afecta a los salmones y que genera grandes pérdidas productivas. Esta era una enfermedad conocida a nivel internacional e impactó fuertemente en la industria nacional. Esto impuso la necesidad de adoptar medidas de emergencia que permitieran abordar la crisis y llevó a modificar gran parte de la normativa ambiental y sanitaria establecida a la fecha para la actividad de acuicultura. La industria voluntariamente acordó una serie de medidas para el control de la enfermedad, pero la magnitud de la crisis y la

${ }^{34}$ Un análisis de la situación provocada por la crisis del virus Isa y sus consecuencias en Chile fue abordado en un estudio co-financiado por Global Aquaculture Alliance y el Banco Mundial y en el que intervinieron la Subsecretaría de Pesca y Salmonchile. Véase Alveal, Adolfo et al., The Recovery of the Chilean Salmon Industry. The Isa cCisis and its Consequences and Lessons (Puerto Montt, 2012), en http://www.gaalliance.org/ cmsAdmin/uploads/GAA_ISA-Report.pdf. 
necesidad de imponer medidas obligatorias, hacían esencial la intervención estatal que asegurara la instauración de medidas adecuadas, no discriminatorias y proporcionadas y la necesaria coordinación de acciones con otros órganos públicos así como con otros usuarios del borde costero y, en último término, a generar mecanismos de apoyo económico por el impacto que se generó en las regiones de Los Lagos y Aysén por la pérdida de empleos.

El Servicio Nacional de Pesca dicta un plan de contingencia para el control de ISA y un plan de control de "Caligus" ${ }^{35}$ pero recién el 8 de octubre de 2008 se dicta por primera vez un programa sanitario específico de vigilancia y control de una enfermedad de alto riesgo de Lista 2, en este caso de ISA ${ }^{36}$.

Los principales objetivos de estos planes y programa fue la detección temprana de la presencia del patógeno basada en el muestreo permanente de los centros de cultivo; establecer restricciones al transporte de ejemplares y mortalidades y el control del "Caligus".

Por primera vez se establece una zonificación sanitaria con restricciones a las zonas infectadas y en vigilancia y a los que se denominaron centros sospechosos y en riesgo, categorías estas últimas que no se encontraban reconocidas expresamente por el RESA. Asimismo, se implementó por primera vez la exigencia de eliminación de ejemplares o de cosecha obligatoria anticipada contemplada en el RESA. sin que existieran cuestionamientos de legalidad o constitucionalidad a su aplicación. Asimismo, se establecieron obligaciones para las diversas etapas de cultivo, tanto desde el punto de vista de las medidas sanitarias que evitaran la diseminación de la enfermedad como con un estricto control del transporte, lo que incluyó prohibición de traslado interregional.

A diferencia del programa sanitario de control, los planes de contingencia dictados no se contemplaban como tales en el RESA. y se dictaron al amparo de las facultades generales de carácter sanitario reconocidas al Servicio Nacional de Pesca.

Por su parte, se establecieron fuertes controles a la importación de ovas de salmones, culminando el año 2008 con la suspensión de importación de ovas desde países que presentaran la enfermedad pancréatica del salmón o PD, por la necesidad de evitar el ingreso de esta otra enfermedad de alto riesgo.

Paralelamente se modificó el RESA ${ }^{37}$ incorporando una definición específica de emergencia sanitaria; extendiendo el control a los prestadores

\footnotetext{
${ }^{35}$ Parásito que afecta a los salmones y que agrava la diseminación del Isa por cuanto provoca heridas que hace más vulnerable al pez portador.

${ }^{36}$ Resolución $N^{\circ} 2.638$ de 2008 del Servicio Nacional de Pesca.

${ }^{37}$ Mediante Decretos supremos No 416 de 2008 y N 349 de 2009 del Ministerio de Economía, Fomento y Turismo.
} 
de servicios como centros de acopio ${ }^{38}$, centros de faenamiento ${ }^{39}$ y las embarcaciones de transporte; se adicionaron medidas a ser adoptadas ante una emergencia y podían aplicarse también a las enfermedades de lista $2^{40}$; se dispuso la facultad de destrucción de redes y artes de cultivo; se incorporó la obligación de ensilar la mortalidad ${ }^{41}$; y se crearon las áreas de manejo sanitario conjunto que consistía en imponer condiciones de operación coordinada entre los centros de cultivo integrantes de una misma área. La medida de coordinación más importante fue el período de descanso de tres meses que debía cumplirse por todos los centros integrantes del área una vez terminada la cosecha para evitar que el virus Isa tuviera huéspedes donde alojarse en ese lapso, lo que obedecía a las recomendaciones científicas.

Esta medida se puso en práctica mediante la resolución $\mathrm{N}^{\circ} 1449$ de 2009 del Servicio Nacional de Pesca que instauró por primera vez las áreas de manejo sanitario, hoy denominadas en la LGPA. agrupación de concesiones, que en este caso son de salmones y que fueron conocidas coloquialmente como los "barrios". Asimismo, la misma resolución estableció una densidad de cultivo máxima para los centros de cultivo de modo de asegurar que no se excediera de un determinado número de peces por jaula a fin de evitar el estrés que propicia la diseminación de enfermedades. Por primera vez, la Autoridad exigía a los productores rebajar la cantidad de peces por jaula lo que impactaba directamente una decisión que históricamente fue considerada propia de la libertad empresarial.

De esta forma se puede apreciar que las modificaciones introducidas al RESA. cambian el enfoque individual asociado a la actividad de cada centro de cultivo, a una visión colectiva que comprende al centro de cultivo, al área circundante (área de manejo sanitario y prestadores de servicios) y a los riesgos pre-frontera (importación).

En el mismo período se modifica el RAMA. ${ }^{42}$ y la resolución acompañante ${ }^{43}$ haciéndolo preventivo, ya que no se podía volver a iniciar un período productivo sin contar con el resultado favorable de un informe ambiental.

${ }^{38}$ Jaulas instaladas fuera de las plantas de procesamiento donde se mantienen los ejemplares en espera de su ingreso a la planta. Son también denominadas estaciones de transferencia. Antes denominados viveros.

${ }^{39}$ Establecimiento donde se lleva a efecto el sacrificio de los ejemplares, antes denominados centros de matanza.

${ }^{40}$ Antes solo podían aplicarse a enfermedades de Lista 1, esto es, las enfermedades que no están presentes en Chile hasta que se detecta un brote y que no se han expandido en el territorio. El Isa era de Lista 2.

${ }^{41}$ Inactivación mediante la aplicación de químicos previo a su traslado.

${ }^{42}$ Decreto supremo N 350 de 2009 del Ministerio de Economía, Fomento y Turismo.

${ }^{43}$ Resolución $N^{\circ} 3612$ de 2009 de la Subsecretaría de Pesca. 
Ante la constatación de anaerobiosis simplemente no se puede volver a sembrar hasta comprobar que se han alcanzado nuevamente niveles de oxígeno que garanticen al menos un período productivo en condiciones aeróbicas. Además se eliminó la excepción referida a la existencia de un accidente geográfico para eximir de la distancia de 1,5 millas entre concesiones de salmones.

Por su parte, la resolución acompañante se modificó haciendo más exigentes los límites de aceptabilidad haciéndolos.

Esta normativa se dictó al amparo de las normas legales que existían a la fecha pero la falta de un sistema infraccional específico para asegurar su cumplimiento así como la necesidad de modificar el título concesional para obtener financiamiento para los titulares de las concesiones mediante la entrega en garantía de las mismas, determinó la necesidad de tramitar una modificación legal que plasmó el cambio de enfoque de la regulación, otorgando un fundamento legal más sólido a lo que se había hecho, ampliando las facultades regulatorias y de fiscalización. La intervención estatal de amplio alcance sobre la actividad económica fundada en una crisis de gran envergadura, se consolidó legalmente a través de la ley 20.434 publicada en el Diario Oficial de 8 de abril de 2010.

\section{Periodo 2010 a 2014.}

En el año 2010 se publicó la Ley $N^{\circ} 20.434$ que vino a completar el nuevo modelo ambiental de la acuicultura y a realizar ajustes a las concesiones. La ley fue complementada en el año 2012 con la Ley $N^{\circ} 20.583$. El nuevo modelo considera los siguientes contenidos:

a) Ordenamien to territorial. Se cierra el acceso a nuevas concesiones de acuicultura de salmones por un plazo de cinco años la región de Los Lagos y de Aysén. El objetivo de la medida era no seguir entregando concesiones de salmones hasta ordenar territorialmente la actividad y no aumentar la carga en los sitios de cultivo hasta que se implementara completamente el nuevo modelo productivo ${ }^{44}$. En la región de Magallanes el cierre fue solo por un año (entre el 8 de abril de 2010 y el 8 de abril de 2011) y su objetivo fue permitir terminar el proceso de zonificación del borde costero del litoral.

Para completar el proceso de ordenamiento se crea la institución de la relocalización de concesiones de salmones ${ }^{45}$ que consiste en que las concesiones otorgadas las pueden ser ubicadas en un nuevo sector (siempre dentro de áreas apropiadas) para conseguir mejores condiciones que propicien un mejor desempeño ambiental y sanitario. No puede aumentarse el número total ni

\footnotetext{
${ }^{44}$ Artículo 2 de la ley 20.434.

${ }^{45}$ Artículo 5 de la ley 20.434.
} 
la superficie de concesiones, por lo cual se debe renunciar a una concesión de las que se es titular para reemplazarla por una nueva en otro sector.

Además se establece la distancia de 1,5 millas de distancia entre los centros de cultivo y los parques y las reservas marinas y se elimina la posibilidad de realizar acuicultura en lagos, ya que se determina que no se podrán establecer áreas apropiadas para la acuicultura en ellos, y en los ríos se permite solo la acuicultura de carácter extensivo ${ }^{46}$.

La zonificación del borde costero del litoral ${ }^{47}$ se incorpora en la LGPA. de modo que en caso de existir una zonificación regional (aprobada por la comisión nacional de uso del borde costero) las áreas apropiadas para la acuicultura deberán adecuarse a ella, rechazándose las solicitudes pendientes en áreas incompatibles.

El agotamiento de las áreas apropiadas para la acuicultura en las regiones de Los Lagos y Aysén impone la necesidad de establecer nuevas áreas pero el procedimiento se ha visto impactado por dos nuevas disposiciones:

i) El Convenio 169 de la OIT sobre Pueblos indigenas y tribales en paises independientes ${ }^{48}$, cuyo artículo 6 impone la necesidad de consultar a los pueblos indígenas las medidas legislativas y administrativas que sean susceptibles de afectarlos directamente. De este modo, la creación de nuevas áreas apropiadas, debe pasar por la consulta a los pueblos indígenas.

ii) La Ley $\mathrm{N}^{\circ} 20.249$ sobre espacio costero marino de pueblos originarios que permite a comunidades indígenas solicitar espacios de borde costero con preferencia sobre toda otra solicitud mientras se resuelve el supuesto de su derecho a acceder a ese espacio: que se acredite el uso consuetudinario que dicho solicitante ha tenido del sector respectivo.

b) Normativa sanitaria. Se incorporan en la LGPA. las agrupaciones de concesiones, antes áreas de manejo sanitario, a las que se impone la coordinación de sus operaciones, de modo que todos los centros empiecen a operar al mismo tiempo y cosechen en la misma época tras lo cual se exigen tres meses de paralización de operaciones a todos conjuntamente (descanso coordinado). También puede imponerse la coordinación de los tratamientos terapéuticos (por ejemplo, el uso de antibióticos). Los integrantes de las agrupaciones pueden acordar otras medidas sanitarias o ambientales más exigentes que las establecidas por la Autoridad mediante un acuerdo denominado "plan de manejo de la agrupación" ${ }^{49}$.

La ley incorporó la necesidad de establecer una densidad de cultivo por

${ }^{46}$ Actual artículo 67 LGPA.

${ }^{47}$ Artículos $2^{\circ} \mathrm{N}^{\circ}$ 57) y 67 LGPA.

${ }^{48}$ Decreto supremo N 236 de 2008 del Ministerio de Relaciones Exteriores por el cual se promulga el Convenio en Chile.

${ }^{49}$ Artículo $52 \mathrm{~N}^{\circ} 2$ letra 52) LGPA; artículo $2 \mathrm{~N}^{\circ} 39$ y Título $14^{\circ} \mathrm{RESA}$. 
agrupación de concesiones. La densidad es la cantidad de biomasa (peces) por $\mathrm{m}^{3}$ de la jaula y es una medida destinada a evitar la sobrepoblación en las jaulas y disminuir el estrés que provoca en los peces y que los hace más susceptibles a contraer y desarrollar una enfermedad ${ }^{50}$.

Como se dijo anteriormente, la normativa prevé normas de protección ambiental pre-frontera (importación), a nivel de las agrupaciones (medidas coordinadas) y del centro de cultivo (procedimientos rutinarios y programas sanitarios). Sin embargo, se incorporó un nuevo nivel denominado macrozonas que son conjuntos de agrupaciones que corresponden a amplias zonas geográficas que abarcan dos o más agrupaciones, estableciéndose amplias distancias entre las distintas macro-zonas. El objetivo es que en el caso del brote de una enfermedad, se prohíba el movimiento de embarcaciones entre macro-zonas y así contener la diseminación de la enfermedad ${ }^{51}$.

Adicionalmente, se incorporan a las distancias existentes entre centros de cultivo ( 1,5 millas), la distancia entre agrupaciones de concesiones y entre macro-zonas pretendiendo de este modo generar unidades de contención de enfermedades. Sin embargo, y debido a que las agrupaciones se crearon sobre las concesiones ya otorgadas y estas últimas en muchos casos no tenían grandes distancias entre sí por la norma que permitía eximir de la distancia de 1,5 millas en los casos que existiera un accidente geográfico, la verdadera innovación está por las distancias que se instauran entre macro-zonas, esto es, se prevén franjas de distancia obligatoria entre macro-zonas quedando aisladas unas de otras.

La ley prevé incentivos para que las concesiones que están en dichas franjas se trasladen con preferencia a otros sitios, en cuanto existan áreas apropiadas, mediante la relocalización hasta el 8 de abril de 2015 (se exime por cinco años del aumento de la patente única de acuicultura que incorporó la ley 20583). A partir de esa fecha se reemplaza el incentivo por una causal de caducidad que consiste en que aquel centro que no fue trasladado, existiendo áreas apropiadas, y que obtenga una clasificación en bioseguridad baja por dos veces, en cualquier periodo, será sancionado con la pérdida de la concesión.

Se incorpora en la LGPA. la posibilidad de establecer medidas y de imponer sanciones por su incumplimiento a los prestadores de servicios, esto es, aquellos que realizan actividades como limpieza, desinfección, transporte, lavado de redes, diagnósticos de enfermedades, monitoreos ambientales, entre otros. Se establece un registro que habilita el ejercicio de la actividad y del que se puede suspender o eliminar al configurarse infracciones a sus obligaciones. Así también se instaura el uso del posicionador satelital para las

\footnotetext{
${ }^{50}$ Artículo 86 bis LGPA.

${ }^{51}$ Artículos 5 y 6 de la Ley $N^{\circ} 20.434$.
} 
embarcaciones que prestan servicios a los centros de cultivo para controlar que cuando exista una zonificación sanitaria, las embarcaciones no pasen desde una zona infectada a una zona libre de la enfermedad contaminando a esta última ${ }^{52}$.

Se reemplaza el reglamento de importación habitual de especies ${ }^{53}$ fortaleciendo la certificación sanitaria para la importación incorporando la metodología del análisis de riesgo para determinar la posibilidad de ingreso al país de especies conforme a un nivel de riesgo aceptable. Todo esto de conformidad con las directrices de la Oficina de Salud Animal, referencia internacional para el comercio internacional.

Además se establecen restricciones productivas a los centros de cultivo y a las agrupaciones según su comportamiento sanitario, teniendo como indicador la clasificación de bioseguridad obtenida en un período productivo y como consecuencia, el nivel de densidad de cultivo que se aplica a la agrupación.

En efecto, en el caso de los centros de cultivo, si su desempeño sanitario da cuenta de altas pérdidas de ejemplares en el período productivo (se presume un mal manejo sanitario, ya que ningún productor propicia una pérdida de producción), se deberá disminuir la cantidad de peces a sembrar en el próximo ciclo. Se entiende que en estos casos el centro de cultivo está clasificado en bioseguridad media o baja. La reiteración de la clasificación en bioseguridad baja implicará la caducidad de la concesión del centro de cultivo.

Por su parte, la clasificación en bioseguridad baja de la agrupación de concesiones (se calcula incorporando el comportamiento de todos los centros de la agrupación) importará una disminución de la densidad de cultivo establecida para toda la agrupación de concesiones, lo que se traducirá en un menor número de peces que pueden ser ingresados a los centros de cultivo integrantes de la agrupación en el próximo periodo productivo pero además ellos deberán ser ingresados a una menor densidad $\left(\mathrm{kg} / \mathrm{m}^{3}\right)$ lo que hace más compleja la operación desde el punto de vista económico si la baja de densidad es muy grande. Esta última medida es de alto impacto porque la densidad se determinará considerando el desempeño ambiental y sanitario colectivo, esto es, resultados de los informes ambientales y de las pérdidas de toda la agrupación, lo que puede traer por consecuencia restricciones de carácter productivo (disminución del número de peces a sembrar) a todos los integrantes de la agrupación y no sólo aquellos que tuvieron un mal desempeño. La única excepción es que si un centro obtiene una clasificación

\footnotetext{
${ }^{52}$ Artículos 86 y 86 ter LGPA.

${ }^{53}$ Decreto supremo $N^{\circ} 72$ de 2011 del Ministerio de Economía, Fomento y Tu-
} rismo. 
en bioseguridad alta y el resto de los centros en baja, sólo él tiene derecho a utilizar una mayor de densidad de cultivo incentivando de este modo, pese a la regulación colectiva, el buen desempeño sanitario individual.

Una medida de reciente establecimiento es el porcentaje de reducción de siembra de la agrupación, que es una medida voluntaria que adoptan los titulares de los centros de cultivo de la agrupación y que consiste en operar con menos peces que el total de ejemplares que resulta de la densidad de cultivo por agrupación, esto es, disminuyen el número total de peces que correspondería a la agrupación pero se aplicará la densidad de cultivo máxima autorizada para centros de engorda y no la que correspondería por el desempeño $\left(17 \mathrm{~kg} / \mathrm{m}^{3}\right)$. Esto se realiza a través de la presentación de un plan de manejo que dé cuenta de este acuerdo entre los integrantes de la agrupación. La ventaja sanitaria y ambiental es la menor cantidad de biomasa (peces) que habrá en cultivo pero al operar con la densidad general propicia la viabilidad económica de la actividad. Al bajar el número de peces totales se podrán aprovechar más eficientemente las jaulas pero con un número menor de peces en la totalidad de la agrupación.

Finalmente, la LGPA reconoce explícitamente la facultad del Servicio Nacional de Pesca para establecer programas sanitarios y que su incumplimiento será sancionado mediante infracciones específicas.

c) Normativa a mbiental: se establece que los INFAs serán elaborados por parte de terceros contratados por el Estado, traspasando la responsabilidad al Servicio Nacional de Pesca quien debe contratar a quienes los realizarán, los que deben estar inscritos en un registro previa acreditación de su experiencia, calidad e independencia. Con esto se rompió el vínculo contractual entre el titular del centro de cultivo y quien debe elaborar el informe ambiental ${ }^{54}$.

Además se agrega la necesidad de regular las condiciones de seguridad de las estructuras de cultivo para evitar los escapes de peces o la pérdida masiva de recursos en sistemas intensivos y los desprendimientos de especies exóticas en sistemas extensivos ${ }^{55}$, estableciéndose una presunción de responsabilidad por daño ambiental en los casos en que constatándose estas situaciones, no se recapture al menos el 10\% de los ejemplares en el plazos de 30 días desde el evento, prorrogables por el mismo plazo ${ }^{56}$.

Se prohíbe el uso preventivo de antimicrobianos (antibióticos) en la acuicultura y la necesidad de regular el uso de desinfectantes.

d) Nuevas infracciones instauradas por la LGPA. vinculadas

\footnotetext{
${ }^{54}$ Artículo 122 bis LGPA.

${ }^{55}$ Artículo 118 ter inciso $11^{\circ}$ LGPA.

${ }^{56}$ Artículo 118 quater LGPA.
} 
a la violación de las nuevas normas ambientales y sanitarias. Las infracciones más graves se sancionan con multa y suspensión de operaciones (infraccionar el descanso obligatorio, la densidad de cultivo, los tratamientos terapéuticos, el reinicio de operaciones sin contar con informe ambiental favorable). La tercera infracción puede llevar a caducidad de la concesión. La Subsecretaría de Pesca aplica la sanción correspondiente en cada caso, previa denuncia e informe del Servicio Nacional de Pesca ${ }^{57}$ y el reclamo se presenta ante el Ministerio de Economía.

e) Nuevas causales de caducidad por incumplimientos de la normativa ambiental y sanitaria. Entre ellas está obtener dos veces informes ambientales con resultados negativos en los centros de cultivo en lagos (los que se obtuvieron antes que se fijara la prohibición de realizar acuicultura en lagos); la reiteración de infracciones graves sancionadas por la Subsecretaría de Pesca conforme al artículo 118 ter LGPA.; la reiteración de la infracción que consiste en que se produzca el escape o desprendimiento de especies en cultivo habiéndose verificado que no se adoptaron las condiciones de seguridad de las estructuras de cultivo ${ }^{58}$.

Cabe destacar que este período da cuenta de dos situaciones totalmente contrapuestas en materia de cultivo de salmones: en el año 2010 a la salida e inicio de la recuperación post crisis, los indicadores sanitarios y productivos fueron muy auspiciosos: disminuyó la mortalidad de ejemplares y aumentó su peso, disminuyó el tiempo requerido para alcanzar tallas comerciales, lo que permite rebajar costos de alimentación entre otros, lo que adicionado al incremento del precio del Salmón del Atlántico, arrojó un auspicioso escenario para la industria salmonera. En el año 2012 estos indicadores cambian lo que coincide con un aumento sustantivo de la producción (ejemplares en cultivo). Así las cosas, la densidad de cultivo aparece como una medida necesaria para prevenir efectos ambientales y sanitarios indeseados.

Finalmente, en este período se instaura una nueva institucionalidad ambiental que comprende el Ministerio del Medio Ambiente, el Servicio de Evaluación Ambiental, la Superintendencia de Medio Ambiente y los Tribunales Ambientales.

\section{EvaluaCión CRÍtica DE LA NORMATIVA AMBIENTAL} APLICABLE A LA ACUICULTURA

\section{Análisis crítico de la normativa ambiental aplicable a la acuicultura.}

A partir de la revisión de la evolución de la normativa ambiental aplicable

\footnotetext{
${ }^{57}$ Artículo 118 ter LGPA.

${ }^{58}$ Artículo 142 LGPA.
} 
a la acuicultura es posible afirmar que si bien se definieron clara y correctamente los objetivos (artículos 86 y 87 LGPA.) no se crearon instrumentos adecuados.

El régimen ambiental de la acuicultura fue particularmente débil en los períodos previos al año 2008. La incidencia de un análisis aislado de la acuicultura, aferrado solo al centro de cultivo, llevó a un tratamiento parcial y equívoco que impidió prevenir los eventos que ya era posible vislumbrar en el año 2003 con la "Política Nacional de la Acuicultura". El crecimiento progresivo de la actividad y la tercerización de procesos no fue constatado oportunamente por la Autoridad dejando vacíos en la regulación, fiscalización y sanción de actividades con un fuerte impacto en el desempeño ambiental.

La ley que dejó a los reglamentos el desarrollo de las medidas que aseguraran el cumplimiento de los objetivos ambientales fue la adecuada para asegurar la suficiente flexibilidad y evolución normativa, pero no contempló un sistema de infraccional y sancionatorio o de incentivos que propendiera al cumplimiento. Esto se constata porque se introdujeron importantes cambios en los reglamentos ambiental y sanitario antes de la ley 20.434 , pero el cambio de las exigencias no era suficiente frente a un sistema infraccional débil. La instauración de un procedimiento sancionatorio administrativo que previera la suspensión de operaciones o causales de caducidad, al menos para las infracciones más graves, aparecen como los elementos de persuasión necesarios para el cumplimiento.

La incorporación de la industria en el diseño y la decisión de las medidas ambientales aplicables a su actividad, fue una decisión legislativa que puso en peligro los objetivos ambientales trazados, especialmente por la consagración de una instancia resolutiva con composición privada como era el Consejo Nacional de Pesca. La creación de instancias consultivas, no resolutivas, con la participación de los particulares que aporten antecedentes sobre la viabilidad de las medidas a implementar parece ser la mejor solución.

En la normativa ambiental de la acuicultura original de los artículos 86 y 87 LGPA, se contemplaba que la dictación de las medidas se requeriría la presentación de informes técnicos de la Subsecretaría de Pesca y del Consejo Nacional de Pesca, instancia de discusión política, económica y social, no técnica o científica, por lo cual dejaba abierta la vía para impedir la instauración de medidas que parecieran adecuadas.

La crisis demostró que ante la emergencia debieron dictarse una serie de normas que no fueron cuestionadas, precisamente por la gravedad de las circunstancias, pero que implicaron un cambio de interpretación de la normativa y que importan al menos plantearse la cuestión acerca de la certeza y la predictibilidad del derecho. Gran parte de los programas sanitarios fueron incorporados al RESA. para que pudieran ser reconocidos sin discusión por 
los tribunales ante la denuncia de su infracción y de allí que el reglamento tuviese que entrar a definir extensos y detallados procedimientos rutinarios que no son propios de una regulación general. Asimismo la regulación de los prestadores de servicios se incorporó en el RESA. y luego en la LGPA.

La normativa resultante post crisis, especialmente la sanitaria, terminó siendo detallada y que opera en la fijación específica de procedimientos y no de objetivos, lo que hace complejo su cumplimiento y fiscalización, rigidiza excesivamente procedimientos que dependen de técnicas que cambian en el tiempo y no se adapta fácilmente a las necesidades de innovación que, permitiendo un buen desempeño ambiental, aseguren la eficiencia económica. Esto es diferente de lo que ocurre con el RAMA. que incorpora objetivos a cumplir, dejando al titular del centro de cultivo el cómo cumplirlos.

La normativa post crisis da cuenta de la perspectiva adoptada por el Estado en el sentido de no discriminar entre aquellas actividades de carácter sanitario que deberían ser de responsabilidad y preocupación individual del titular del centro de cultivo, de aquéllas que efectivamente ponen en riesgo a otros actores o a la actividad en general. Así las cosas, se produjo una sustitución de roles entre la responsabilidad empresarial por su actividad y la responsabilidad estatal por el resguardo del patrimonio ambiental.

En materia de ordenamiento territorial la superposición de instrumentos sin las necesarias normas de conciliación (áreas apropiadas para la acuicultura y zonificación del borde costero del litoral), provocan conflictos y dudas de interpretación aún vigentes hoy ${ }^{59}$, a lo que se adiciona nueva normativa que genera la extensión en el tiempo de los trámites (procedimiento de consulta indígena para la declaración de nuevas áreas apropiadas).

La acuicultura presenta alta heterogeneidad pero ello no se traduce suficientemente en la normativa, salvo en el caso del umbral que define los proyectos que se someten o no al sistema de evaluación de impacto ambiental. y a la definición de categorías para la elaboración del CPS y del informe ambiental, no existen mayores distinciones que den cuenta de la distinta realidad que se presenta en cada caso.

${ }^{59}$ La zonificación del borde costero de la región de Aysén se aprobó por el Decreto supremo $N^{\circ} 153$ de 2004 del Ministerio de Defensa Nacional que reenviaba la especificación de sus disposiciones a la "Memoria explicativa" de la misma. Dicha memoria daba cuenta de una serie de condiciones que debían ser cumplidas por los usos que pretendían ejercerse en áreas preferentes para otros usos. La "Memoria" original aprobada en la región no fue tomada razón por la Contraloría General de la República, la que determinó la eliminación de algunas condiciones previstas en la misma. La memoria a que hace alusión el decreto no corresponde a la memoria original, no obstante que esta última fue la difundida por las Autoridades regionales, ordenándose recién este año por el órgano contralor la publicación íntegra de este importante instrumento que define las especificaciones conforme a las cuales debe aplicarse el instrumento. 
El cambio de enfoque desde una perspectiva individual a otra colectiva que incluye la regulación de los prestadores de servicios y a las agrupaciones de concesiones, es adecuado para abordar la diseminación de enfermedades. Por su parte, el denominado plan de manejo que pueden acordar los integrantes de las agrupaciones de concesiones y que puede incluir medidas voluntarias más exigentes que las instauradas por la autoridad y que por su aprobación adquieren el carácter de obligatorias y fiscalizables ${ }^{60}$, deben contemplar adecuadamente la concurrencia libre del concesionario a los acuerdos. En efecto, las medidas sanitarias están asociadas a un mejor desempeño ambiental pero al mismo tiempo, pueden constituirse en mecanismos de exclusión de competidores. Así por ejemplo, el acuerdo acerca de los centros de cultivo que deben descansar por un período productivo o la aplicación de tratamientos terapéuticos costosos, pueden llegar a afectar el ejercicio de la actividad económica del concesionario. De este modo, la exigencia de quórum que asegure la libre concurrencia a los acuerdos y el no sometimiento a condiciones gravosas por voluntad de otros particulares es un punto de especial relevancia en este nuevo instrumento.

\section{Perspectivas de una regulación ambiental de la acuicultura futura.}

La regulación ambiental de la acuicultura debe considerar la experiencia del pasado, incorporando los nuevos instrumentos de la LGPA. En efecto, la modificación introducida a través de la Ley $\mathrm{N}^{\circ} 20.657$ adicionó al objetivo de preservación de los recursos hidrobiológicos contenido en el artículo 1 LGPA., el objetivo de la conservación y el uso sustentable de los recursos hidrobiológicos, mediante la aplicación del enfoque precautorio, de un enfoque ecosistémico en la regulación pesquera y la salvaguarda de los ecosistemas marinos en que existan esos recursos contenido en el artículo $1 \mathrm{~B}$.

Es relevante destacar que esta norma está contenida dentro del título $1^{\circ}$ de la ley, referido a las disposiciones generales, aplicables a todas las actividades sometidas a la ley, incluida la acuicultura. Si bien el artículo $1 \mathrm{C}$ aplica estos nuevos instrumentos en forma explícita a la administración pesquera, el artículo $1 \mathrm{~B}$ tiene una formulación general.

La admisión del enfoque precautorio constituye un instrumento al que debe acudirse ante situaciones que por razones de oportunidad, impidan esperar los resultados de los estudios que otorguen todos los datos necesarios para adoptar una decisión. Esto se basa en que las nuevas disposiciones de la LGPA, si bien consagran el enfoque precautorio, establecen asimismo un marco de obtención de información científica que funda las decisiones públicas. De este modo, se reconoce el rol público que ejerce el Instituto de

${ }^{60}$ Artículo $2 \mathrm{~N}^{\circ} 52$ LGPA. 
Fomento Pesquero en materia de investigación científica para la regulación; se incorporan normas que separan las recomendaciones científicas de las propuestas de la Autoridad y de la intervención de los actores; y se consagra el análisis y la discusión de la información generada por comités científicos cuyas recomendaciones solo pueden basarse en ciencia y no en elementos sociales y económicos. Debe generarse un marco general que permita a la Autoridad acudir al enfoque precautorio ante la falta de completa certidumbre del riesgo de daño pero sí con evidencia científica sobre la posibilidad de su acaecimiento ${ }^{61}$.

El enfoque ecosistémico y la salvaguarda de los ecosistemas marinos importan necesariamente su aplicación en materia de acuicultura. En primer lugar, porque la regulación de la ley de pesca, en sus disposiciones generales se aplican a todas las actividades contempladas en el artículo $1^{\circ}$, entre ellas la acuicultura. En segundo lugar, porque el enfoque ecosistémico consiste en la consideración de todos los usos y actores que inciden en el ordenamiento de un determinado sector. Así las cosas, no podría entenderse la aplicación de un enfoque ecosistémico a la pesca sin considerar que dicha actividad comparte los mismos sectores con la acuicultura y con otras actividades de diversa índole. En tercer lugar, porque el enfoque ecosistémico es precisamente el que debería orientar la instauración o modificación de instrumentos de planificación espacial que permita superar las deficiencias detectadas por la sobreposición en el tiempo de diversos instrumentos de ordenamiento territoriales ${ }^{62}$, inconsistentes en su aplicación con los objetivos trazados y con problemas de diseño que impiden incorporar fácilmente en ellos procedimientos nuevos sobrevinientes que evite traslape de competencias y extensión excesiva de los trámites (como la consulta indígena).

Por su parte, la salvaguarda de los ecosistemas marinos en que existen los recursos hidrobiológicos da cuenta, más que de un nuevo instrumento, de un nuevo objetivo que se adiciona o complementa al de la conservación y el uso sustentable de los recursos. Así las cosas, el mandato de la LGPA importa la necesidad de considerar en la determinación de nuevas áreas destinadas a la acuicultura, los factores ambientales que propicien un buen desempeño

${ }^{61}$ La aplicación del principio precautorio está contemplado explícitamente en la estrategia medioambiental para la industria acuicultora noruega que es el primer productor mundial de salmón, de allí que resulte interesante la referencia. Norwegian Ministry of Fisheries and Coastal Affairs, Strategy for an environmentally sustainable Norwegian Aquaculture Industry (Oslo, 2009), en http://www.regjeringen.no/upload/FKD/Vedlegg/Diverse/2009/strategy\%20for\%20an\%20sustainable\%20aquaculture.pdf

${ }^{62}$ Soto, Doris, (coordinador), Desarrollo de la acuicultura. Enfoque ecosistémico (Roma, 2011), en http://www.fao.org/docrep/014/i1750s/i1750s.pdf 
ambiental y la prevención de conflictos con otros usos, incluidas las demandas de los pueblos indígenas.

Debe diferenciarse los ámbitos de actuación estatal de los aspectos de detalle que dependen de la responsabilidad empresarial. De este modo, la importación de especies hidrobiológicas y la regulación en sus aspectos colectivos importan la necesaria intervención estatal (programas sanitarios, agrupación de concesiones, macro-zonas, zonificación sanitaria, entre otras), invirtiéndose esta regla en el ámbito de los centros de cultivo, imponiendo a estos últimos objetivos a cumplir y no formas de darle cumplimiento. Así, el Estado no controla los procedimientos pero castiga un mal desempeño sanitario.

\section{CONClusiones}

$1^{\circ}$ La evolución del régimen ambiental de la acuicultura en Chile da cuenta de una serie de circunstancias que impidieron en determinados momentos, el cumplimiento de los objetivos trazados. Debe superarse la falta de certeza de la regulación, la carencia de herramientas para enfrentar eventos indeseados imprevistos, la falta de coordinación y superposición de instrumentos que abordan los mismos aspectos, la carencia de fundamento científico en las decisiones y su confusión con elementos sociales y económicos que pueden llevar demorar u omitir medidas necesarias.

$2^{\circ} \mathrm{Al}$ tratarse de una actividad regulada, se puede incurrir en una sobreregulación al confundir los objetivos estatales de resguardo del patrimonio ambiental, con el resguardo del patrimonio particular del cultivador poco eficiente o con un mediocre desempeño ambiental. El esfuerzo regulador del Estado debería centrarse en los aspectos colectivos del nuevo régimen, fijando al centro de cultivo individual los objetivos ambientales a cumplir con los incentivos adecuados para conseguirlo junto a un sistema infraccional y sancionatorio eficiente para castigar su incumplimiento.

$3^{\circ} \mathrm{La}$ regulación futura de la acuicultura debe considerar la experiencia del pasado, generando disposiciones flexibles, claras, transparentes, que cumplan con los objetivos de la conservación y el uso sustentable de los recursos hidrobiológicos y la salvaguarda de los ecosistemas en que existen, utilicen los nuevos instrumentos instaurados en ella (enfoque precautorio y ecosistémico), integren adecuadamente la información científica y que otorguen una participación justa, acotada y oportuna a los actores en el diseño de las normas. 


\section{BIBLIOGRAFÍA}

Alveal, Adolfo y otros, The Recovery of the Chilean Salmon Industry. The Isa Crisis and its Consequences and Lessons (Puerto Montt, 2012), en http://www.gaalliance.org/ cmsAdmin/uploads/GAA_ISA-Report.pdf.

Norwegian Ministry of Fisheries and Coastal Affairs, Strategy for an environmentally sustainable Norwegian Aquaculture Industry (Oslo, 2009), en http://www. regjeringen.no/upload/FKD/Vedlegg/Diverse/2009/strategy\%20for\%20an\%20 sustainable\%20aquaculture.pdf

Sото, Doris, (coordinador), Desarrollo de la acuicultura. Enfoque ecosistémico (Roma, 2011), en http://www.fao.org/docrep/014/i1750s/i1750s.pdf 
